\title{
Prevalence of Risk Factors and Protective Factors of Breast Cancer in Yasuj City, Iran
}

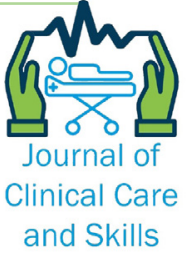

\section{ARTICLE INFO}

\section{Article Type}

Descriptive Study

\section{Authors}

Manzouri L. ${ }^{* 1} M D$,

Parhizkar S. ${ }^{1} P h D$,

Amiri S. ${ }^{2} M D$

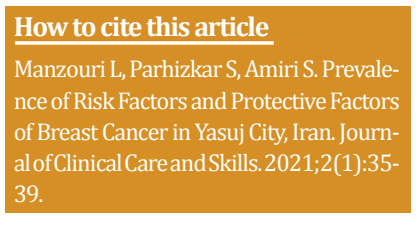

\section{A B S T R A C T}

Aims Breast cancer with known risk factors and preventive factors is one of the most important health concerns and the most common cancer among women worldwide. This study was conducted to assess breast cancer risk factors and protective factors in women aged 20-69 years in Yasuj, Iran.

Instruments \& Methods In this descriptive cross-sectional study, a total of 492 women aged 20-69 years were selected through systematic random sampling method. Data were collected through a demographic checklist and a checklist of potential and proven risk factors and protective factors based on textbooks and the Up To Date web site. Data analysis was performed by SPSS 16 software using descriptive statistics.

Findings The most common risk factors were overweight $(41.1 \%)$, obesity $(27.2 \%)$, and exposure to smoking (27.6\%). Among the probably protective factors, the most frequent were breastfeeding for at least 16 months (83.5\%), then the number of pregnancy $\geq 5$ (33.5\%), and normal BMI after menopausal (18.5\%).

Conclusion The most common risk factors and protective factors are modifiable and related to the lifestyles.

Keywords Breast Cancer; Risk Factors; Protective Factors; Iran
${ }^{1}$ Social Determinants of Health Research Center, Yasuj University of Medical Sciences, Yasuj, Iran

${ }^{2}$ Committee of Student Research, Yasuj University of Medical Sciences, Yasuj, Iran

\section{*Correspondence}

Address: Faculty of Medicine, Yasuj University of Medical Sciences, Yasuj, Iran. Postal Code: 7591974719.

Phone: +98 (74) 33235146

Fax: +98 (74) 3323515

manzourileila@gmail.com

\section{Article History}

Received: August 15, 2020

Accepted: September 19, 2020

ePublished: February 01, 2021

\section{I T A T I O N L I N K S}

[1] Salehiniya H. Epidemiology and trends in breast cancer mortality in iran [2] Prevalence of breast cancer in Isfahan Province, Iran [3] Premenopausal Breast Cancer Collaborative: A pooling project of studies participating in the national cancer institute cohort consortium [4] Risk factors and preventions of breast cancer [5] Breast cancer in Iranian woman: Incidence by age group, morphology and trends [6] The economic burden of breast cancer in Iran [7] A ten-year study on the prevalence and frequency of risk factors for breast cancer in Sabzevar, Iran [8] Risk factors of breast cancer in Dezful city of Iran: A case-control study [9] Breast cancer status in Iran: Statistical analysis of 3010 cases between 1998 and 2014 [10] Cancer incidence in Iran in 2014: Results of the Iranian national population-based cancer registry [11] Factors that modify breast cancer risk in women [12] Prevalence of breast cancer risk factors in women (20-69 years old) in Isfahan [13] Assessment of risk factors for breast cancer among women under 50 years old [14] Prevalence of breast cancer risk factors in Japan [15] Breast cancer risk factors. Prz Menopauzalny [16] Relevance of risk factors of breast cancer in women: An eastern Indian scenario [17] Prevalence of breast cancer risk factors in women aged 20-69 years in Dehaghan in 2012 [18] An investigation of breast cancer risk factors in Cyprus: A case control study [19] Prevalence, risk factors and disease knowledge of breast cancer in Pakistan [20] Prevalence of risk factors for breast cancer in German airline cabin crew: A crosssectional study [21] Assessment of certain breast cancer risk factors during reproductive age in women in Mashhad (2002-2003) [22] Risk factors of breast cancer in women of Golestan provice: A case conyrol study [23] Breast cancer in Iran: An epidemiological review 


\section{Introduction}

Breast cancer is a major health concern [1], the most common cancer among women worldwide [2-4] and the first cause of cancer death $[1,5]$ in both developed and developing countries [6], and its incidence is estimated to be 1.7 million by 2020 [2], accounting for $25 \%$ of female cancer every year [2-7]. The incidence of breast cancer in the East Mediterranean Region (EMRO) has reported that 27 per 100000 female populations [8]. In Iran, breast cancer is the most frequent malignancy in women, and its peak incidence is in the fourth to fifth decades of life ${ }^{[9]}$ with a standardized age rate (ASR) of 27.4 (95\% CI,22.535.9) [2]. In Kohgiluye and Boyer-Ahmad province (Southwest of Iran), breast cancer is the most frequently identified type of malignancy among women, with an average annual crude incidence rate of 19.42 an ASR of 21.82 per 100000 female population, accounting for $25.41 \%$ of female cancer in 2014 [10]. Given that, the incidence of breast cancer is gradually increasing. The high economic burden of it (in Iran, it was US\$947374468, and most of the cost was related to the productivity lost due to breast cancer deaths and the direct medical cost accounted for nearly $17 \%$ of the estimated total cancer) and its negative effects on mental health, socioeconomic status and quality of life of patients and other family members, having data about the prevalence of risk factors and preventive factors of breast cancer is necessary [6].

About one-half of newly diagnosed breast cancers can be explained by known risk factors [11], such as aging, age at menarche, first live birth and menopause, personal and family history of breast cancer, gene mutation, unhealthy lifestyle, overweight and obesity assessed as body mass index (BMI), lack of breastfeeding, hormone replacement therapy (HRT), smoking, alcohol consumption, chest radiation in adolescence, proliferative breast disease, previous use of oral contraceptive pills [5] that has been mentioned in several studies in Iran (Isfahan, Kermanshah, Dehaghan, Dezful) and other countries such as Poland, China, London, Japan, India, Cyprus, Pakistan $[3,4,7,8,11-19]$. In general, breast cancer risk factors can be divided into behavioral (modifiable) and non-behavioral (non-modifiable). Lifestyle is a major changeable risk factor of breast cancer that can be efficiently controlled by individuals, and awareness of this factor can significantly increase their perceived susceptibility towards a healthy lifestyle and self-care behaviors [7]. On the other hand, breastfeeding for at least 12 months, and physical activity are two important changeable protective factors that may decrease the possibility of developing breast cancer [11].

Based on the subjects mentioned above, it is very important to assess and clarify the prevalence of risk factors and protective factors of breast cancer in women. Given that life, style is different in various parts of Iran, and it has an important role in developing modifiable risk factors; on the other hand, there is a lack of data about this matter in Yasuj (Iran); this study was conducted to investigate the prevalence of risk factors and protective factors of breast cancer in resident women in Yasuj (Iran) to enable policymakers and health care providers to design and implement necessary interventions to modify risk factors and strengthen protective factors.

\section{Instrument \& Methods}

This descriptive cross-sectional study was conducted in urban health centers of Yasuj in 2019. There are five urban health centers in Yasuj, and the electronic health file of all women is available from an integrated national health system as the framework. A total of 492 women aged 20-69 years were selected through a systematic random sampling method. A representative sample size of 492 women was calculated at the 95\% confidence level, the average prevalence of breast cancer risk factors was 0.17 in Isfahan (Iran) [12], and d was 0.2. After explaining the study's purpose, the written informed consent was taken from all women for their participation in the study, and they were reassured that their information was confidential.

Data were collected through a demographic checklist and a checklist of potential and proven risk factors and protective factors based on textbooks and the Up To Date website.

Women completed the questionnaires themselves. If someone was illiterate, her questionnaires were completed by the researcher.

Data analysis was performed using SPSS 16 software. Quantitative variables were presented as mean \pm SD, and Qualitative variables were presented as counts (frequencies).

\section{Findings}

The mean age of women was $41.45 \pm 12.67$ years old. Out of 492 women, 460 (93.5\%) were married, 102 (20.7\%) were employed, and 130 women (26.4\%) were menopause. The mean BMI was $27.5 \pm 4.3 \mathrm{Kg} / \mathrm{m}^{2}$. Reproductive characteristics of participants have been shown in Table 1.

Table 1) Reproductive characteristics of women aged 2069 years

\begin{tabular}{lcc}
\hline \multicolumn{1}{c}{ Variables } & Mean \pm SD & Median \\
\hline Parity (number) & $3.50 \pm 2.30$ & 3 \\
Delivery (number) & $3.08 \pm 2.18$ & 3 \\
Abortion (number) & $0.44 \pm 0.75$ & 0 \\
Age of menarche & $13.17 \pm 1.99$ & 13 \\
Age at first live birth (years) & $21.09 \pm 5.15$ & 20 \\
$\begin{array}{l}\text { Age of menopause (years) } \\
\text { The total duration of } \\
\text { breastfeeding (months) }\end{array}$ & $49.13 \pm 5.41$ & 50 \\
\hline
\end{tabular}

The most common risk factors were overweight (41.1\%), obesity (27.2\%), and exposure to smoking 
(27.6\%). Personal history of breast, colorectal, ovarian, and endometrial cancer, history of radiotherapy to the chest, and Alcohol consumption were not reported by anyone (Table 2 ).

The frequency of protective factors that may reduce breast cancer risk was ordered as 1- breastfeeding for at least 16 months: 411 (83.5\%), parity $\geq 5$ : 154 (33.5\%), and normal BMI after menopause: 24 (18.5\%).

Table 2) Frequency of related risk factors to breast cancer of women aged 20-69 years

\begin{tabular}{|c|c|}
\hline Variables & No. (\%) \\
\hline Early menarche & $84(17.1)$ \\
\hline First, live birth after 30 years old & $17(4)$ \\
\hline Late menopause & $16(12.3)$ \\
\hline Overweight & $202(41.1)$ \\
\hline Obesity & $134(27.2)$ \\
\hline $\begin{array}{l}\text { History of breast cancer in the first-degree } \\
\text { family }\end{array}$ & $15(3)$ \\
\hline Personal history of breast cancer & 0 \\
\hline HRT more than five years & $2(2.39)$ \\
\hline Radiotherapy to chest & 0 \\
\hline Alcohol consumption & 0 \\
\hline Smoking & $71(14.4)$ \\
\hline Second-hand smoker & $136(27.6)$ \\
\hline Night shift work & $14(13.73)$ \\
\hline Personal history of ovarian cancer & 0 \\
\hline $\begin{array}{l}\text { History of ovarian cancer in the first- } \\
\text { degree family }\end{array}$ & $1(2)$ \\
\hline Personal history of endometrial cancer & 0 \\
\hline $\begin{array}{l}\text { History of endometrial cancer in the first- } \\
\text { degree family }\end{array}$ & $7(1.4)$ \\
\hline Personal history of colorectal cancer & 0 \\
\hline $\begin{array}{l}\text { History of colorectal cancer in the first- } \\
\text { degree family }\end{array}$ & $20(4.1)$ \\
\hline Overweight after menopause & $52(40)$ \\
\hline Obesity after menopause & $54(41.5)$ \\
\hline
\end{tabular}

\section{Discussion}

The most frequent modifiable risk factors were considered overweight, second-hand smokers, obesity, and smoking in the current investigation.

In the study by Winter et al., the mean BMI was about $22 \mathrm{Kg} / \mathrm{m} 2$ [20] in the normal range despite our study $\left(27.5 \mathrm{Kg} / \mathrm{m}^{2}\right)$. This difference can be due study population, which assessed the risk factors of breast cancer in the German airline cabin crew. Aich's study in India shows that the mean BMI in the control group was $23.7 \pm 4.7 \mathrm{Kg} / \mathrm{m}^{2}[16]$, which was normal and lower than our results. Also, $30 \%$ and $22 \%$ of participants had overweight and obesity, respectively, which is lower than our findings ( $41 \%$ and $27 \%$ ) and may be related to the difference in race and geographic location of residence. In the Rouhparvarzadeh study, only $9 \%$ of women were obese [12]. This discrepancy may be justifiably ethnicity, lifestyle, and tendency to obesity in women. According to Hadjisavvas and his colleagues, $39 \%$ and $23 \%$ of women were overweight and obese, respectively ${ }^{[18]}$.

More than $25 \%(27.5 \%)$ of women in our study reported a history of exposure to a smoker at home.
In the Badrian study in Dehaghan, $27.5 \%$ were passive smokers [17]. Also, in a study by Fathi and her colleagues in Mashhad, 25.6\% were second-hand smoker [21] which are in concordance with our results. Nevertheless, in the Rouhparvarzadeh study, only $8.7 \%[12]$ of women reported exposure to a smoker, approximately one-third compared to our study. In a study by Jafarinia et al., exposure to a smoker was reported by $39 \%$ of women ${ }^{[8]}$. These differences may be due to sociocultural differences. According to our results, $14.4 \%$ of women were smokers, which is very higher than other conducted studies in Iran, such as $0.2 \%{ }^{[17]}$ and $0.4 \%{ }^{[12]}$ in 2012 , respectively. This difference can be explainable with the increased prevalence of smoking in women since recent years, customs, ethnicity, and sociocultural factors. On the other hand, the results of our study are nearly similar to Hadjisavvas in Cyprus (18.7\%) [18] and Winter in German (12.6\%) ${ }^{[20] .}$

Regarding age at menarche, the mean age of menarche was $13.17 \pm 1.99$ years in our study, and $17 \%$ had early menarche. In a study by Aich et al. mean age of menarche was $13.47 \pm 1.6$ years, and $7.8 \%$ had early menarche [16]. In Hadjisavvas's study, early menarche was reported by $11.4 \%$ [18]. The results of one study in Yasuj (Iran) in 1997, the mean age of menarche was $13.50 \pm 1.33$ that is similar to our study after two decades [22]. In the findings of another study in Iran, the mean age of menarche was $13.42 \pm 1.42$ [23] and $13.14 \pm 1.5$ [23] that are in concordance to our results, too.

Regarding early menarche, it was reported by $3.94 \%$ and $4.6 \%$ in Badrian [17] and Rouhparvarzadeh [12] studies, respectively. Nevertheless, it is very lower in comparison to our results. This difference may be due to ethnicity and climate differences.

Our study results showed that the mean age at first live birth was $21.09 \pm 5.15$ years and in $17 \%$ of women, first live birth was after 30 years old. In the studies of Besharat et al. [22] and Mousavi et al. [23], the mean age at first live birth was $21.56 \pm 18.61$ and $19.40 \pm 4.5$ years, respectively. The maximum age at first live birth was 23 in Fathi Najafi et al.'s study [21]. These results are similar to our findings. In Winter $e t$ al. [20], age at first live birth was higher (32 years old) in German airline cabin crew that can be reasonable due to their jobs. In another study in Japan, it was $26.4 \pm 3.5$ years. It should be considered that many factors such as sociocultural factors, tendency to have a high-level academic education, increasing age of marriage can influence the age at first live birth. The results of studies in Iran, regarding the age at first pregnancy $\geq 30$ years, were $2.6 \%$ in Dezful [8], 2\% in Isfahan [12], and $1.2 \%$ in Dehaghan [17]. It was $0.09 \%$ in India [16] and $10.5 \%$ in Cyprus [18], too. This high difference may be due to increased marriage age, the tendency to delay childbearing, and the increased divorce rate in Iran in recent years.

In our study, the mean age of menopause was $49.13 \pm 5.41$, and late menopause was reported by 

very lower in comparison to our findings. It may be due to a higher percentage of overweight and obesity in women of this region. Also, genetics has an important role in predisposing women to late-onset menopause.

HRT for more than five years was reported by $204 \%$

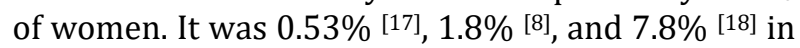
a study by Badrian et al., Jafarinia et al., and Hadjisavvas et al., respectively. Wide variation in HRT consumption may be related to the severity of symptoms, level of tolerance, differences in geographic location, race, and ethnicity.

About $14 \%$ of women reported night shift work in our study, whereas it was $0.2 \%{ }^{[12]}$ and 0 [17] in Dehaghan and Isfahan, respectively. It can be explainable by socioeconomic factors in different provinces of Iran.

Any women in this study did not report alcohol consumption. It should be considered that alcohol consumption is forbidden in Iran that can influence the true answer. In studies by Rouhparvarzadeh [12] and Badrian et al. [17], it was $0.1 \%$ and $0.06 \%$, respectively.

There was no report of a personal history of breast, ovary, endometrial and colorectal cancer in this study. Radiotherapy to the chest was not reported by anyone, too.

Family history of breast cancer in the first-degree family was positive in $3 \%$ of women. It was positive in $0.7 \%{ }^{[12]}, 0.86 \%{ }^{[17]}, 2.3 \%{ }^{[16]}, 2.2 \%{ }^{[14]}$ and $9 \%{ }^{[18]}$ in Isfahan (Iran), Dehaghan (Iran), Mashhad (Iran), India and Japan, respectively. According to the present study results, family history of the ovary, endometrium, and colorectal cancer was positive in $2 \%, 1.4 \%$, and $4 \%$ of women, respectively. It was overlaid positive in $0.4 \%{ }^{[12]}$ and $0.46 \%$ [17] in Rouhparvarzadeh and Badrian et al.'s study, respectively. Given that genetic and environmental factors have a role in developing breast cancer, differences in the results are not unexpected.

Based on our findings, more than $80 \%$ of postmenopause women were overweight and obese, which is very high, and the necessity of implementing some interventions such as lifestyle modification is felt.

Breastfeeding as a protective factor was positive in more than $80 \%$ of women. Mead's breastfeeding duration was more than five years, and $50 \%$ of women had to breastfeed for more than four years. In

the study by Rouhparvarzadeh [12], Badrian et al. [17], and Jafarinia et al. [8], 83.5\%, 88\%, and 78.5\% had breastfed for more than two years, respectively that are in concordance with our results. Nevertheless, in the study of Hadjisavvas et al. [18], only $24 \%$ of women had to breastfeed for more than one year. Also, the average duration of lactation in Aich et al. ${ }^{[16]}$ study was about 25 months.

Mean and median parity was $3.5 \pm 2.3$ and 3 , respectively, in our study, and one-third of women had parity $\geq$ of 5 . In Aich et al., 18\% had parity $\geq 5$, and median parity was 3 [16]. The results of Hadjisavvas et al. ${ }^{[18]}$ showed that $44 \%$ of women had three or more children. Given that socioeconomic and cultural factors play an important role tendency to childbearing, Differences are acceptable. On the other hand, in Iran, increasing the age of marriage, the tendency to delay childbearing, and having one to two children in most families are the probable causes of decreasing parity. In this study, based on sampling, none of the samples had breast cancer, So we could not predict risk factors and protective factors.

\section{Conclusion}

Overweight, obesity and smoking exposure were the most common risk factors related to lifestyle and modified. Given that most of the women were housekeepers, the necessity of changing their lifestyle is felt. On the other hand, planners and policymakers should implement some interventions for healthy lifestyles, focusing on a nutritional diet, effective physical activity, and disadvantages of smoking and exposure to it. Also, training women about breast cancer risk and protective factors via mass media and health care providers is essential. Besides, it enables policymakers and health care providers to design and implement necessary interventions to modify risk factors and strengthen protective factors.

Acknowledgments: The authors are grateful to the respected vice president of Yasuj University of Medical Sciences's technical and research department for the provision of facilities for this project. Additionally, we thank all participated women who assisted us in performing this project.

Ethical Permissions: The ethics committee of Yasuj University of Medical Sciences approved this research (IR.YUMS.REC. 1396.123).

Conflict of Interests: None declared by Authors.

Authors' Contributions: Manzouri L. (First author), Introduction author/Methodologist/Original researcher/Statistical analyst/Discussion author (60\%); Parhizkar S. (Second author), Introduction author/Assistant researcher/Discussion author (30\%); Amiri S. (Third author), Introduction author/Assistant researcher/Discussion author (10\%).

Funding/Sources: This manuscript was extracted from the MD thesis of Samira Amiri with ethic code yums.REC.1396.123, and was supported financially by the deputy of research of Yasuj University of Medical Sciences. 


\section{References}

1- Enayatrad M, Amoori N, Salehiniya H. Epidemiology and trends in breast cancer mortality in iran. Iran J Public Health. 2015;44(3):430-1. [Persian]

2- Tolou-Ghamari Z. Prevalence of breast cancer in Isfahan Province, Iran. Women's Health Bull. 2018;5(4):1-4. [Persian]

3- Nichols HB, Schoemaker MJ, Wright LB, Macgowan C, Brook MN, MacClain KM, et al. Premenopausal Breast Cancer Collaborative: A pooling project of studies participating in the national cancer institute cohort consortium. Cancer Epidemiol Biomark Prev. 2017;26(9):1360-9.

4- Sun YS, Zhao Z, Yang ZN, Xu F, Lu HJ, Zhu ZY, et al. Risk factors and preventions of breast cancer. Int J Biol Sci. 2017;13(11):1387-97.

5- Rafiemanesh H, Salehiniya H, Lotfi Z. Breast cancer in Iranian woman: Incidence by age group, morphology and trends. Asian Pac J Cancer Prev. 2016;17(3):1393-7.

6- Daroudi R, Sari AA, Nahvijou A, Kalaghchi B, Najafi M, Zendehdel K. The economic burden of breast cancer in Iran. Iran J Public Health. 2015;44(9):1225-33. [Persian]

7- Hashemian M, Akbarzadeh R, Khosroabadi AA, Asadi ZS, Salehabadi S, Hoseini BL. A ten-year study on the prevalence and frequency of risk factors for breast cancer in Sabzevar, Iran. J Midwifery Reprod Health. 2016;4(3):673-8. [Persian]

8- Jafarinia B, Bahadorzai M, Delpisheh A, Sayehmiri K, Tavakoli M. Risk factors of breast cancer in Dezful city of Iran: A case-control study. Tehran Univ Med J. 2016;74(2):135-9. [Persian]

9- Akbari ME, Sayad S, Sayad S, Khayamzadeh M, Shojaee L, Shormeji Z, et al. Breast cancer status in Iran: Statistical analysis of 3010 cases between 1998 and 2014. Int J Breast Cancer. 2017;2017:1-10.

10- Roshandel G, Ghanbari-Motlagh A, Partovipour E, Salavati F, Hasanpour-Heidari S, Mohammadi G, et al. Cancer incidence in Iran in 2014: Results of the Iranian national population-based cancer registry. Cancer Epidemiol. 2019;61:50-8.

11- Chen WY. Factors that modify breast cancer risk in women [Internet]. Waltham: UpToDate, Inc; Unknown Year [Unknown Cited]. Available from: https:// www.uptodate.com/contents/factors-that-modify-breast- cancer-risk-in-women.

12- Rouhparvarzadeh N. Prevalence of breast cancer risk factors in women (20-69 years old) in Isfahan. Iran Q J Breast Dis. 2014;7(1):52-61. [Persian]

13- Marzbani B, Taymoori P, Nouri B. Assessment of risk factors for breast cancer among women under 50 years old. J Sch Public Health Inst Public Health Res. 2017;15(1):4760. [Persian]

14- Mizota Y, Yamamoto S. Prevalence of breast cancer risk factors in Japan. Jpn J Clin Oncol. 2012;42(11):1008-12.

15- Kaminska M, Ciszewski T, Lopacka-Szatan K, Miotla P, Staroslawska E. Breast cancer risk factors. Prz Menopauzalny. 2015;14(3):196-202.

16- Aich R, Mondal NK, Chhatui B, Sepai HM, Aich R, Acharyya A, et al. Relevance of risk factors of breast cancer in women: An eastern Indian scenario. J Cancer Res Ther. 2016;12(1):302-8

17- Badrian M, Ahmadi P, Amani M, Motamedi N. Prevalence of breast cancer risk factors in women aged 2069 years in Dehaghan in 2012. Iran J Dis Breast.2014;7(2):67-75. [Persian]

18- Hadjisavvas A, Loizidou MA, Middleton N, Michael T, Papachristoforou R, Kakouri E, et al. An investigation of breast cancer risk factors in Cyprus: A case control study. BMC Cancer. 2010;10:447.

19- Asif HM, Sultana S, Akhtar N, Rehman JU, Rehman RU. Prevalence, risk factors and disease knowledge of breast cancer in Pakistan. Asian Pac J Cancer Prev. 2014;15(11):4411-6.

20- Winter M, Blettner M, Zeeb H. Prevalence of risk factors for breast cancer in German airline cabin crew: A crosssectional study. J Occup Med Toxicol. 2014;9:27.

21- Farhadi M, Daneshi A, Tabatabaii A, Sotoudeh M, Salek Moghaddam AR, Shamshiri AR. Assessment of certain breast cancer risk factors during reproductive age in women in Mashhad (2002-2003). Razi J Med Sci. 2004;11(42):587-95. [Persian]

22- Besharat S, Motie MR, Besharat M, Roshandel G. Risk factors of breast cancer in women of Golestan provice: A case conyrol study. Iran J Obstet Gynecol. 2011;13(6):4651. [Persian]

23- Mousavi SM, Montazeri A, Mohagheghi MA, Mousavi Jarrahi A, Harirchi I, Najafi M, et al. Breast cancer in Iran: An epidemiological review. Breast J. 2007;13(4):383-91. 